\title{
MARKETING DE RELACIONAMENTO EM BIBLIOTECAS UNIVERSITÁRIAS
}

\section{EL MARKETING RELACIONAL EN LAS BIBLIOTECAS UNIVERSITÁRIAS}

\author{
Keina Maria Guedes da Silva - keinaguedes@yahoo.com.br \\ Bacharel em Biblioteconomia pela Universidade Federal do Ceará (UFC). \\ Hamilton Rodrigues Tabosa - hatabosa@yahoo.com.br \\ Professor do Departamento de Ciências da Informação da Universidade \\ Federal do Ceará (UFC). Doutorando do Programa de Pós-Graduação em \\ Ciência da Informação da Universidade Federal da Paraíba (UFPB).
}

\section{RESUMO}

Introdução: Aborda o marketing de relacionamento em biblioteca universitária, tendo como objeto de estudo o Setor de Assistência ao Leitor da Biblioteca de Ciências Humanas (BCH) da Universidade Federal do Ceará, e as relações existentes entre os bibliotecários de referência e os usuários.

Objetivo: Investigar, junto à direção e aos bibliotecários de referência da $\mathrm{BCH}$, o conhecimento que eles têm sobre marketing de relacionamento, se veem a importância de fazer uso desse tipo de marketing para melhor satisfazer os usuários, que ações de marketing de relacionamento são praticadas, como são praticadas e se praticam de forma consciente, bem como verificar, junto aos usuários da biblioteca, sua percepção dessa prática e seu grau de satisfação quando às ações de marketing de relacionamento desenvolvidas.

Metodologia: consiste em uma pesquisa de caráter exploratório, com abordagem qualitativa. Utilizou-se o funcionalismo e, como instrumento para a coleta de dados, optou-se pela entrevista semiestruturada e questionários. Para analisar os dados, optou-se pela análise de conteúdo.

Resultados: Verificou-se que o conhecimento que a diretora da $\mathrm{BCH}$ e os bibliotecários de referência têm sobre marketing de relacionamento ainda é muito restrito, e embora vejam a importância do tema no âmbito da $\mathrm{BCH}$, as ações que praticam são de forma inconsciente, o que deixa lacunas quanto à percepção dos usuários em relação a essas práticas. 
Conclusões: Independente do tipo de ações, os usuários apresentaram um grau considerável de satisfação em relação às ações praticadas pela $\mathrm{BCH}$.

Palavras-chaves: Marketing. Marketing de relacionamento. Biblioteca universitária.

\section{INTRODUÇÃO}

As unidades de informação têm como principal objetivo atender as necessidades informacionais de seus usuários, e isso não se mostra diferente em uma biblioteca universitária. Aos bibliotecários desse tipo de unidade de informação, cabe o grande desafio de garantir a satisfação das necessidades e desejos informacionais dos usuários e avaliar o grau de satisfação dos mesmos em relação aos produtos e serviços informacionais que são ofertados. Para Silva (2000, p. 5) "o marketing pode representar uma ferramenta de apoio indispensável ao desempenho do profissional da informação."

Amaral (1996, p. 208) defende o pressuposto da "aplicação das técnicas de marketing, no sentido de valorizar a imagem dos serviços de informação e do bibliotecário, quebrando barreiras na comunicação entre a biblioteca e os usuários, visando melhor atender às suas necessidades."

Assim sendo, o marketing de relacionamento surge como uma alternativa que viabiliza a construção de relacionamento com o cliente e a conquista da fidelidade dos mesmos, pois visa atender suas necessidades e seus desejos de forma individualizada, oferecendo produtos e serviços personalizados, com o propósito de adequar a oferta de serviços e produtos às demandas específicas, como declara Mendes (2007, p. 9): “[...] o marketing de relacionamento assume grande importância, fornecendo a chave para reter os clientes, envolvendo laços estruturais para mantê-los fieis, atendendo as suas necessidades e desejos e ainda individualizando e personalizando seus serviços."

Este artigo mostra o marketing de relacionamento aplicado a uma biblioteca universitária, tomando como objeto de estudo a Biblioteca de Ciências Humanas $(\mathrm{BCH})$ da Universidade Federal do Ceará, focando o Setor de Assistência ao Leitor (forma como o Sistema de Bibliotecas da UFC nomeia o setor de Referência), sabendo que tal instituição visa satisfazer às necessidades informacionais dos seus 
usuários nos âmbitos do ensino, da pesquisa e da extensão, contemplando um público de grande diversidade, visto que a $\mathrm{BCH}$ abrange um acervo direcionado às várias áreas de conhecimento das Ciências Humanas. Procuramos compreender como se dá o uso do marketing de relacionamento por parte da diretora e dos bibliotecários de referência que atuam na $\mathrm{BCH}$, focando as relações existentes entre os bibliotecários de referência e os usuários e como as ações de marketing de relacionamento promovidas pela $\mathrm{BCH}$ são percebidas pelos usuários.

Afirma Amaral (2000, p. 9) acerca do conhecimento das técnicas de marketing em unidade de informação: "o conhecimento das técnicas de marketing aplicável nas unidades de informação certamente poderá contribuir para desenvolver novas e úteis habilidades para os profissionais da informação. Eles deverão conhecer o mercado que atuam."

\section{MARKETING: UMA BREVE ABORDAGEM CONCEITUAL E HISTÓRICA}

Ao longo de vários anos muitos autores vêm conceituando o termo marketing à luz dos mais diversos olhares, uma vez que o marketing combina ciência e arte envolvendo diferentes áreas do conhecimento como a administração, antropologia, psicologia, economia, cultura, história, estatística e outras.

Rocha e Christensen (1999, p. 15), definem marketing como:

[...] uma orientação da administração, uma filosofia, uma visão. Essa orientação reconhece que a tarefa primordial da organização é satisfazer o consumidor, atendendo as suas necessidades, levando em conta o seu bem-estar a longo prazo, respeitadas as exigências e limitações impostas pela sociedade e atendidas as necessidades de sobrevivência e continuidade da organização.

Essa definição está mais voltada para o foco gerencial, evidenciando a aplicabilidade do marketing na área administrativa, seus objetivos e benefícios para as organizações. No entanto, Kotler e Keller (2006, p. 4) em seus estudos ressaltam que o marketing não se limita apenas ao campo gerencial, podendo ser também um "processo social pelo qual indivíduos e grupos obtêm o que necessitam e desejam por meio da criação, da oferta e da livre troca de produtos e serviços de um valor com outros". Esse conceito social do marketing mostra o seu papel desempenhado 
na sociedade, colocando o individuo, com suas necessidades e desejos, como ator principal dos processos gerenciais do marketing.

A American Marketing Association (2004 apud AMARAL, 2007, p. 5), conceitua marketing associando seu lado gerencial e social, quando o define como "uma função social e um conjunto de processos que envolvem a criação, a comunicação e a entrega de valor para os clientes, bem como a administração do relacionamento com eles, de modo que beneficie a organização e o seu público interessado", destacando a entrega de valor para o cliente, bem como a administração do relacionamento com eles.

Em síntese, marketing pode ser entendido como um processo gerencial e social que visa atender e satisfazer os desejos e necessidades de um determinado público-alvo por meio de trocas de produtos e serviços que geram valor às partes envolvidas nesse processo.

Inicialmente, o surgimento do marketing está relacionado diretamente com o comércio e com a venda de produtos, no entanto, com as evoluções e revoluções vivenciadas pela sociedade, principalmente com os avanços da industrialização e globalização, o marketing passa a ganhar importância, e os seus conceitos e modelos vem se redesenhando para melhor se adaptarem à realidade de uma sociedade que agora se caracteriza pelo consumismo (COSTA, 1996).

Consequentemente, esse novo cenário social desencadeou uma acirrada competição entre os mercados, onde não bastava mais desenvolver e produzir produtos e serviços a custo competitivo, pois, com essa nova sociedade caracterizada pelo consumo, surgem também clientes mais exigentes e com o poder de escolher produtos e serviços que melhor thes propusessem uma relação favorável de custo-benefício. Dessa forma, o cliente passou a dominar o cenário da comercialização, e o marketing sofre uma reconfiguração para colocar o cliente como a razão e o foco de suas ações.

Percebe-se, com isso, que o marketing deixa seu caráter de soberania do produto e passa a dar ênfase à soberania do cliente. Fazendo surgir uma orientação de marketing voltada para o cliente, na construção de relacionamentos lucrativos com eles e, assim, fazendo surgir o marketing de relacionamento. 


\section{MARKETING DE RELACIONAMENTO}

Tendo como foco principal o consumidor e a criação de parceria com ele, surge o marketing de relacionamento durante a década de 1990. Década esta, marcada por grandes avanços tecnológicos, e consequentemente, pela expansão comercial, empresarial e mercadológica. Esses fatores evidenciaram ainda mais 0 crescimento da concorrência entre os mercados, os quais buscam sua sobrevivência não só gerando produtos atraentes com qualidade e ofertando serviços inusitados a baixo custo, mas também, e principalmente, criando parcerias com seus clientes, buscando construir relações com eles. $O$ relacionamento com os clientes passa a ser, então, a principal arma competitiva entre os mercados (COBRA, 2003).

McKenna (1999, p. 150) afirma que:

O marketing de relações é essencial ao desenvolvimento de liderança, fidelidade do consumidor e rápida aceitação de novos produtos e serviços do mercado. [...] em um mundo onde o cliente tem tantas opções, mesmo em segmentos limitados, uma relação pessoal é a única forma de manter a fidelidade do cliente.

Essa afirmativa declara o marketing de relacionamento como uma estratégia de negócio não só para a criação de relações com os clientes, mas também para sua fidelização. Kotler e Armstrong (2004) reforçam essa ideia quando afirmam que a chave para a construção de relacionamentos com os clientes é a criação de valor e satisfação superiores para eles, e quanto maior o valor e a satisfação gerada pelo produto ou serviço, maior também é a probabilidade de se tornarem clientes fiéis.

O marketing de relacionamento, portanto, configura-se numa nova forma de praticar o marketing, seja como uma ferramenta estratégica ou como uma filosofia administrativa. Nessa perspectiva, percebemos que as bibliotecas universitárias podem fazer uso do marketing de relacionamento como uma vantagem competitiva que viabiliza o alcance dos seus objetivos e da sua valorização, assim como a construção de relações favoráveis com os usuários. 


\section{MARKETING DE RELACIONAMENTO EM BIBLIOTECA UNIVERSITÁRIA}

Sabe-se que uma biblioteca universitária, assim como qualquer outra unidade de informação, tem o claro objetivo de prestar produtos e serviços que atendam as necessidades informacionais de um determinado público. Nesse sentido, o marketing pode ser compreendido como "uma filosofia de gestão administrativa na qual todos os esforços convergem em promover, com a máxima eficiência possível, a satisfação de quem precisa e de quem utiliza produtos e serviços de informação." (OTTONI, 1995, p. 1).

Silva $(2000$, p. 5) reforça essa ideia e vai além quando diz que:

[...] com a adoção de uma filosofia de marketing, as bibliotecas poderão melhorar sua imagem, atrair novos usuários e prestar serviços que poderão representar maior satisfação por parte dos usuários, obtendo com isso melhor posição na indústria da informação, que lhes garanta sua sobrevivência.

Outros autores como Amaral (2000), Oliveira (2008), Baptista (2007) e Silveira (2009), concordam com Silva e com Ottoni em se adotar uma filosofia de marketing na gestão de uma biblioteca, e da utilização de todos os recursos que o marketing pode proporcionar para a valorização da biblioteca e do bibliotecário.

Por essa ótica, percebe-se a importância da adoção desse tipo de pensamento por parte dos bibliotecários, neste caso, os que atuam em biblioteca universitária, para que se possa fazer uso do marketing de forma favorável à biblioteca e aos clientes/usuários, aliando a tecnologia, as técnicas biblioteconômicas e o marketing para melhor atendê-los, adequando os produtos e serviços às necessidades, desejos e expectativas do público-alvo, potencializando também as redes de relações com os clientes/usuários, primando pela ética, a qualidade e a boa convivência, adotando uma atitude de simpatia e empatia na oferta da informação.

Acredita-se que a ênfase do marketing de relacionamento vai além de reconhecer a importância de tratar cada cliente de forma individualizada, mas também o reconhecimento da importância de lançar produtos de forma personalizada, que no âmbito das bibliotecas universitárias, essa ênfase do marketing de relacionamento irá contribuir na oferta da informação e na 
customização dos produtos de informação para que se adequem o máximo possível às necessidades de cada usuário. Essa personalização do produto informacional refere-se à $3^{\text {a }}$ lei de Ranganathan, "para cada livro o seu leitor", ou seja, embora haja uma grande diversidade de usuários em uma biblioteca universitária, o marketing de relacionamento oferece subsídios para que esta atenda satisfatoriamente a toda essa diversidade, com produtos específicos e direcionados a cada diferença, necessidade e preferência do usuário.

Contudo, não é só na personalização do produto que se deve pensar, mas também na personalização do ambiente que cerca o produto. As instalações físicas da biblioteca fazem parte do conjunto de atributos e condições que envolvem o produto informacional que esta tem a oferecer, e devem ser devidamente adequadas às necessidades físicas e psíquicas dos usuários que frequentam a biblioteca e fazem uso de seus recursos. É imprescindível que a ambientação da biblioteca ofereça um bem-estar, visando não só manter e fidelizar os usuários reais, mas também conquistar e encantar usuários potenciais, pelas qualidades dos produtos, da ambientação e também dos serviços.

O marketing de relacionamento proporciona ao bibliotecário uma maior de aproximação com os usuários. Em conseqüência disso, há um estímulo maior para um diálogo aberto dos bibliotecários com os usuários e vice-versa, possibilitando um feedback importante para o aprimoramento dos serviços e produtos da biblioteca (AMARAL, 1996).

Fraga et al. (2008) reforçam essa ideia quando afirmam que o marketing pode contribuir para a construção de concepções sociais sobre o bibliotecário que vão além dos estereótipos construídos, valorizando-o e favorecendo a quebra dos estigmas a cerca da imagem da profissão.

Quanto à questão do atendimento, é comum os investimentos das bibliotecas nas tecnologias da informação e comunicação para automação dos serviços, tendo em vista a otimização e eficiência do atendimento ao usuário. No entanto, não é somente a utilização das tecnologias que irá bastar para se oferecer um atendimento satisfatório aos usuários, faz-se necessário também que as pessoas que trabalham fazendo o atendimento ao público busquem atendê-lo com a máxima qualidade. Do ponto de vista do usuário, a qualidade do atendimento se dá pelo julgamento das ações do próprio atendente, ou seja, muitos usuários formam a ideia da biblioteca 
por meio do primeiro contato e das primeiras impressões construídas durante o atendimento pessoal, conforme Baptista (2007).

Para sintetizar esta abordagem sobre o marketing de relacionamento em biblioteca universitária seguem algumas sugestões de operacionalização desse processo pontuadas em três perspectivas, com base nas sugestões de Teixeira e Freitas (2004):

\section{Quanto aos funcionários da biblioteca:}

Aceitar e compreender uma política de marketing de relacionamento; Treinar para utilizar eficazmente as potencialidades do marketing de relacionamento; Estabelecer uma rotina de consulta por todos os funcionários ao banco de dados dos clientes/usuários da biblioteca; Estudar os clientes/usuários com um olhar mercadológico e do ponto de vista dessa clientela; Adotar uma postura de vendedores ativos de informação; Desenvolver e manter bons relacionamentos com os clientes/usuários; Estar acessível aos clientes/usuários; Desenvolver produtos e serviços de informação personalizados e adequados aos desejos, expectativas e necessidades dos clientes/usuários; Treinar todo o pessoal para prestar excelência no atendimento aos clientes/usuários; Trabalhar pela qualificação de uma imagem profissional e institucional; Promover por meio de ações positivas a biblioteca; Aliar as tecnologias da informação e comunicação às interações interpessoais com os clientes/usuários; Desenvolver atividades de relações públicas; Desenvolver atividades de motivação entre os funcionários da biblioteca; Desenvolver a sensibilidade e criatividade dos funcionários da biblioteca; Agir com empatia e simpatia em relação aos clientes/usuários; Estabelecer comunicação direta com os clientes/usuários; Estabelecer um cronograma permanente de reuniões para discutir casos e levantamento de sugestões.

\section{Quanto à estrutura física:}

Planejar estrategicamente o espaço físico; Disponibilizar mobiliário ergonômico; lluminar adequadamente; Climatizar 0 ambiente; Sinalizar adequadamente o acervo; Diversificar o acervo em conteúdo, forma e suporte; Tornar o ambiente acessível a todos; Estabelecer programas de limpeza e manutenção a fim de se ter tudo sempre funcionando satisfatoriamente; Dispor de 
um ambiente de convivência e socialização, com lojas de conveniência onde se possa interagir e fazer uma pausa para o lanche; Instalar os balcões de atendimento do mais próximo os clientes/usuários; Dispor de área de multimídia com acesso livre à internet; Dispor de espaços de estudo individuais e em grupo; Apresentar um layout harmonioso.

\section{Quanto aos clientes/usuários:}

Construir um banco de dados com informação sobre os clientes/usuários; Estabelecer uma rotina permanente de coleta de informações sobre os clientes/usuários; Criar programas e eventos que atraiam os clientes/usuários para a biblioteca; Oferecer um tratamento especializado com profissionalismo, cortesia, empatia e simpatia; Ofertar serviços personalizados; Construir relações com os clientes/usuários por meio da qualidade dos produtos e serviços, da ambientação favorável e da excelência no atendimento; Apresentar atitudes de valorização dos clientes/usuários; Dar atenção e presteza na solução dos problemas dos clientes/usuários.

Atualmente, a $\mathrm{BCH}$ conta com um amplo espaço físico climatizado, com rampas de acesso e banheiros adaptados a cadeirantes. Possui um rico acervo constituído de livros, periódicos, folhetos, teses, dissertações, fitas de vídeo, CDROM entre outros, voltado para os alunos dos cursos de graduação e pósgraduação, aos docentes, pesquisadores e funcionários da UFC, assim como ao público em geral para pesquisa local. A esse público é oferecido serviços de livre acesso ao acervo, empréstimo domiciliar, treinamento e orientação de uso da biblioteca e normalização de trabalhos acadêmicos, serviço de referência, entre outros.

\section{APLICAÇÃO METODOLÓGICA}

Partiu-se de um levantamento bibliográfico e documental e optou-se por uma pesquisa de abordagem qualitativa, através do método funcionalista. Quanto aos sujeitos pesquisados, foram selecionados a diretora da $\mathrm{BCH}$, por ser a gestora das ações de marketing de relacionamento praticadas na instituição, os bibliotecários de referência da $\mathrm{BCH}$, por se relacionarem de forma direta com os usuários, e vinte 
usuários da biblioteca, com intuito de verificar como as ações de marketing de relacionamento são percebidas por eles. Estabeleceu-se essa amostra por tratarmos de uma abordagem qualitativa que prioriza não a quantidade, mas a tentativa de analisar e explicar em profundidade o significado e as características das informações coletadas (OLIVEIRA, 2008).

A escolha dos usuários se deu de forma intencional, optando-se por aqueles que estudavam, no momento da pesquisa, no ambiente de atuação direta dos bibliotecários de referência, excetuando os estudantes de Biblioteconomia, por terem uma visão diferenciada sobre o bibliotecário.

Como instrumentos para coleta de dados, optou-se por uma entrevista semiestruturada com a diretora e os bibliotecários de referência, aliando também informações coletadas por meio de questionários constituídos de perguntas de múltipla escolha, aplicados junto aos usuários da $\mathrm{BCH}$, o que possibilitou uma maior precisão de dados, com a finalidade de comparar o que está sendo feito em relação ao marketing de relacionamento pela $\mathrm{BCH}$ e como isso é percebido pelos usuários.

Quanto aos questionários, foram elaborados com perguntas abertas e fechadas, porém, foi realizado um pré-teste desse questionário com dez participantes e observou-se que a maioria deles não respondia às perguntas abertas, o que limitaria a análise qualitativa dos dados. Com base nas opiniões justificadas por alguns dos usuários que participaram da pesquisa, elaborou-se um novo questionário com perguntas de múltipla escolha, com diversas possíveis respostas, abrangendo várias facetas sobre o assunto questionado.

Foi realizado um total de quatro entrevistas: com a diretora da $\mathrm{BCH}$, com a bibliotecária responsável pelo Setor de Assistência ao Leitor e com mais duas bibliotecárias que também atuam nesse setor. Todas as entrevistas foram gravadas para não correr o risco de perder nenhum detalhe e ser fiel à transcrição das respostas dos entrevistados.

Foi aplicado um total de 34 questionários para a validação de vinte, pois além do critério de selecionar apenas os usuários que estavam estudando no 1ำ piso da biblioteca, exceto os estudantes de Biblioteconomia, foi feito também uma seleção dos usuários que fazem uso frequente dos produtos e serviços da $\mathrm{BCH}$. A frequência de uso foi determinada para aqueles que fazem uso dos produtos e serviços da $\mathrm{BCH}$ pelo menos três dias por semana, ou seja, mais da metade dos dias em que a 
biblioteca está aberta ao público, levando em conta que ela está disponível ao público durante os cinco dias úteis da semana.

Quanto à técnica para analisar os dados obtidos, utilizou-se a análise de conteúdo, que foi concebida em cinco etapas, de acordo com o modelo de Moraes (1999):

1. Preparação das informações: durante essa etapa foram feitas várias leituras de todos os materiais coletados a fim de selecionar quais efetivamente estavam de acordo com os objetivos e critérios da pesquisa, bem como possibilitou uma apreensão global das principais ideias das mensagens e seus significados.

2. Seleção das unidades de análise: nessa etapa foi realizada uma releitura de todo o material selecionado para delinear as unidades de análise, as quais foram definidas por tema, ou seja, palavras, sentenças, frases, parágrafos ou textos inteiros, os quais representam indícios das temáticas referentes ao conteúdo dos dados coletados, do embasamento teórico do estudo e das interpretações do pesquisador. Neste estudo foram delineadas 13 unidades de análise que foram categorizadas em três grandes categorias.

3. Processo de categorização: foram criadas três categorias temáticas não apriorística, ou seja, a partir dos dados e do contexto das respostas dos sujeitos pesquisados, do referencial teórico que embasou o estudo e dos objetivos da pesquisa, obedecendo a um critério semântico para classificar e agrupar as unidades de análise de acordo com as semelhanças e analogias de sentido existentes entre elas.

4. Descrição do conteúdo: nessa etapa foi descrita uma síntese do conteúdo explícito das mensagens analisadas, apresentando citações diretas das respostas dos sujeitos pesquisados, de acordo com as categorias e unidades de análise criadas.

5. Interpretação do conteúdo: essa foi a etapa em que se buscou ir além da descrição das mensagens analisadas, e chegar a uma compreensão mais aprofundada do seu conteúdo, por meio de inferências e interpretações das linhas e entrelinhas de todo conteúdo analisado, explorando seus significados com base nas teorias do referencial teórico. 
Assim, para a elaboração de nossa análise, foram criadas três categorias e 13 unidades de análise, com base nos dados e no contexto das respostas dos sujeitos pesquisados, no referencial teórico do estudo, nos objetivos da pesquisa e nas interpretações do pesquisador, que estão sintetizadas no quadro a seguir:

Quadro 1 - Síntese das categorias e unidades de análise

\begin{tabular}{|c|c|}
\hline CATEGORIAS & UNIDADES DE ANÁLISE \\
\hline $\begin{array}{c}1 \text { MARKETING DE } \\
\text { RELACIONAMENTO }\end{array}$ & $\begin{array}{lll}1.1 \text { Conhecimento sobre } & \text { marketing } & \text { de } \\
\text { relacionamento. } & & \\
1.2 \text { Importância do marketing } & \text { de } \\
\text { relacionamento. } & & \\
1.3 \text { Ações de marketing de relacionamento. } & \\
\text { 1.4 Percepção sobre marketing } & \text { de } \\
& \text { relacionamento pelos usuários. }\end{array}$ \\
\hline $\begin{array}{c}2 \text { RELACIONAMENTO } \\
\text { BIBLIOTECÁRIO DE REFERÊNCIA X } \\
\text { USUÁRIOS }\end{array}$ & $\begin{array}{l}\text { 2.1 Conhecimento sobre os usuários } \\
\text { 2.2 Conhecimento sobre o Setor de Assistência } \\
\text { ao Leitor da BCH. } \\
\text { 2.3 Identificação e reconhecimento do } \\
\text { bibliotecário de referência. } \\
\text { 2.4 Acessibilidade aos usuários. } \\
\text { 2.5 Construção de relações com os usuários. }\end{array}$ \\
\hline 3 SATISFAÇÃO & $\begin{array}{l}\text { 3.1 Satisfação com os produtos da } \mathrm{BCH} \text {. } \\
\text { 3.2 Satisfação com a ambientação física da } \\
\text { BCH. } \\
\text { 3.3 Satisfação com os serviços da } \mathrm{BCH} \text {. } \\
\text { 3.4 Grau de satisfação dos usuários da } \mathrm{BCH} \text {. }\end{array}$ \\
\hline
\end{tabular}

Fonte: Elaborado pelos autores.

\section{ANÁLISE E INTERPRETAÇÃO DOS DADOS}

\section{CATEGORIA 1: MARKETING DE RELACIONAMENTO}

\section{Conhecimento sobre marketing de relacionamento (Unidade de análise} 1.1)

De um modo geral, o conhecimento que a diretora e os bibliotecários de referência da $\mathrm{BCH}$ têm sobre marketing de relacionamento é limitado, se comparado a toda abrangência e funcionalidade do marketing de relacionamento. Há uma percepção da noção parcial dos meios do marketing de relacionamento, embora, os fins do marketing de relacionamento ainda não sejam bem visualizados por esses bibliotecários. Pois, conhecer as necessidades da clientela é apenas o primeiro 
passo para ofertar produtos e serviços que satisfaçam suas necessidades, e que por meio dessa satisfação se chegue aos fins do marketing de relacionamento que é a construção de relações que fidelizem os clientes.

Observou-se certa tendência a definir o marketing de relacionamento nos termos gerais do marketing, associando-o à propaganda de produtos e serviços. No entanto, notou-se um interesse pelo assunto, e que já há uma articulação da diretora com os demais bibliotecários em relação ao estudo do marketing e do marketing de relacionamento, em discussões com comissões não só da $\mathrm{BCH}$, mas de todo o Sistema de Bibliotecas da UFC.

\section{Importância do marketing de relacionamento (Unidade de análise 1.2)}

Mais uma vez ficou notória uma forte associação do marketing à propaganda e uma indissociação das especificidades do marketing de relacionamento ao marketing. Percebeu-se que eles ainda confundem o marketing de relacionamento, que é algo mais específico e focado nas relações com os clientes, com o marketing, que é algo mais geral e que vai além da mera propaganda de um produto ou serviço.

Ficou a impressão de que os bibliotecários entrevistados veem a importância de alguma ação de marketing no auxílio da divulgação dos produtos e serviços da biblioteca, no conhecimento sobre o usuário e no atendimento das suas necessidades informacionais, mas não necessariamente de ações de marketing de relacionamento.

\section{Ações de marketing de relacionamento (Unidade de análise 1.3)}

Percebeu-se que há a preocupação de ofertar bons serviços, tanto no Setor de Assistência ao Leitor quanto no balcão de circulação de materiais. A biblioteca procura oferecer uma boa ambientação e conhecer os usuários, suas necessidades e interesses para adequarem seus produtos e serviços. Há cursos de treinamento para informá-los sobre os produtos e serviços que a biblioteca dispõe, para que desfrutem ao máximo dos seus recursos informacionais. Todas essas ações relatadas se caracterizam como ações de marketing de relacionamento, de acordo com Kotler (2000).

No entanto, percebeu-se que essas ações de marketing não são praticadas de forma consciente, ou seja, com o foco no marketing de relacionamento, uma vez 
que eles focam os usuários pensando prioritariamente nos serviços para a satisfação dos mesmos, e não focando os usuários prioritariamente pensando nas relações para fidelizá-los, sendo exatamente isso que 0 marketing de relacionamento prioriza, como afirma Silveira (2009, p. 32).

\section{Percepção do marketing de relacionamento pelos usuários (Unidade de} análise 1.4)

Considerando Santos (2008), foram considerados três pontos pelos quais o marketing de relacionamento pode ser percebido pelos usuários, que são: os produtos, os serviços e a ambientação. De um modo geral, de acordo com as respostas dos usuários referentes a esses três pontos, inferiu-se que ficou também uma lacuna quanto à percepção dos usuários em relação às práticas de marketing de relacionamento na $\mathrm{BCH}$.

\section{CATEGORIA 2: RELACIONAMENTO BIBLIOTECÁRIO DE REFERÊNCIA X} USUÁRIOS

\section{Conhecimento sobre os usuários (Unidade de análise 2.1)}

Percebeu-se que a principal forma que os bibliotecários de referência da $\mathrm{BCH}$ buscam para conhecer os usuários é por meio do estudo de usuário, reconhecendo a importância de conhecê-los para melhor atender suas necessidades informacionais, com base também em dados fornecidos pelo Sistema Pergamum.

No entanto, esse estudo de usuário que é feito pela $\mathrm{BCH}$ tem uma média de intervalo de dois anos, e sendo uma biblioteca um organismo vivo e em constante crescimento, fazer estudos de usuários com uma frequência maior favorece um maior conhecimento dos usuários.

\section{Conhecimento sobre o Setor de Assistência ao Leitor da BCH (Unidade} de análise 2.2)

Constatou-se que dos vinte usuários que responderam ao questionário, 18 declararam não conhecer o Setor de Assistência ao Leitor, e apenas dois afirmaram conhecê-lo. Essa informação mostra que mesmo com todos os esforços por parte dos bibliotecários de referência em divulgar os serviços e produtos da $\mathrm{BCH}$, ainda há 
uma lacuna quanto ao pleno conhecimento dos recursos da biblioteca pelos usuários.

Alguns usuários justificaram o seu desconhecimento pelo Setor de Assistência ao Leitor pelo fato de não haver nenhuma sinalização visual da indicação desse setor. É importante oferecer uma orientação visual aos usuários para que eles possam usufruir de todos os recursos que a biblioteca dispõe.

\section{Identificação e reconhecimento dos bibliotecários de referência} (Unidade de análise 2.3)

Constatou-se que, dos vinte usuários participantes da pesquisa, 13 relataram reconhecer os bibliotecários de referência da $\mathrm{BCH}$ pelo fato de estarem quase todos os dias estudando na biblioteca e não porque eles sejam facilmente identificáveis. Quatro disseram sentir dificuldade em identificá-los pelo fato de não usarem algo que os identifique como tal e três disseram não reconhecê-los.

A sinalização de uma biblioteca é algo que não diz respeito só à sinalização dos setores e serviços, à sinalização do acervo e à sinalização institucional, inclui também a sinalização ou identificação de quem atua na biblioteca.

Seria interessante que o Sistema de Bibliotecas da UFC ponderasse a possibilidade de adotar algum meio de identificação visual também para os bibliotecários, o que facilitaria sua identificação e favoreceria o direcionamento dos usuários a esses profissionais.

\section{Acessibilidade aos usuários (Unidade de análise 2.4)}

Averiguou-se que a visão de acessibilidade dos bibliotecários de referência da $\mathrm{BCH}$ está mais focada nos aspectos físicos e arquitetônicos, quanto ao aspecto da interação pessoal. De acordo com os relatos dos bibliotecários entrevistados, os usuários da $\mathrm{BCH}$ apresentam um perfil mais independente quando buscam informações, solicitando pouco o serviço de referência, o que os faz se mostrarem mais acessíveis somente no momento em que são solicitados. No entanto, mais importante que estar acessível é se mostrar acessível. Embora a maioria dos usuários da $\mathrm{BCH}$ seja independente quando buscam informação, há que se pensar também na minoria que chega à biblioteca sem conhecê-la. Essa proximidade com 
os usuários implica também no aumento das possibilidades de construir e estabelecer relacionamentos favoráveis com os mesmos.

Em contrapartida, foi coletada a opinião dos usuários para saber se eles consideram os bibliotecários de referência acessíveis ao público. Dos vinte participantes, apenas 14 disseram sim, pois sempre que solicitam ajuda são atendidos.

\section{Construção de relações com os usuários (Unidade de análise 2.5)}

Averiguou-se que a diretora tem a preocupação de que o corpo de funcionários se capacite por meio de cursos de reciclagem, como o de Relacionamento Interpessoal e Atendimento ao Cliente, para que se relacione com o público prestando um bom atendimento.

Mas, é notável que essa tentativa de se relacionar com os usuários prestando um bom atendimento mostra-se numa posição passiva, uma vez que, atendem da melhor maneira possível para satisfazer os usuários e em consequência estabelecer relações com os mesmos, porém, somente quando são procurados. Eles nunca se prontificam, nunca oferecem ajuda.

O marketing de relacionamento anula a passividade, pois ele busca ativamente construir relações, e não espera que os clientes deem o primeiro passo para essa construção.

Entretanto, já foi relatado o pouco conhecimento sobre as reais potencialidades do marketing de relacionamento pelos bibliotecários da $\mathrm{BHC}$, o que os distancia de uma visão estratégica baseada no marketing de relacionamento, que possibilitaria uma ampliação das percepções deles sobre outras formas de se relacionar com os usuários.

\section{CATEGORIA 3: SATISFAÇÃO}

\section{Satisfação com os produtos da BCH (Unidade de análise 3.1)}

Um dos maiores problemas identificados nas respostas dos usuários que participaram da pesquisa é sua não satisfação com os produtos e serviços da biblioteca por desejarem que eles fossem mais personalizados. Talvez essas lacunas percebidas, quanto à satisfação total dos usuários da $\mathrm{BCH}$ em relação aos 
seus produtos, advenham do pouco conhecimento que a diretora e os bibliotecários de referência têm sobre marketing de relacionamento e da falta de um embasamento consciente nessa filosofia, que pode ser aliada às práticas biblioteconômicas para a ampliação de uma visão mercadológica que se antecipe às necessidades informacionais dos usuários sem deixar de lado os desejos informacionais dos mesmos, viabilizando uma personalização dos seus produtos, favorecendo não só a ofertando de produtos informacionais necessários, mas também produtos informacionais desejados, no momento que são desejados e da forma que são desejados.

\section{Satisfação com a ambientação física da BCH (Unidade de análise 3.2)}

Constatou-se que dos vinte usuários que responderam ao questionário, 17 declararam estar satisfeitos com a ambientação física da $\mathrm{BCH}$, como iluminação, climatização, silêncio, mobiliário e acesso livre a internet, e apenas três, apesar de também terem se declarado satisfeitos com a ambientação física, fizeram uma contestação quanto ao silêncio e a climatização: gostariam que houvesse mais silêncio e que o ambiente não ficasse tão frio a ponto de causar desconforto.

No tocante à ambientação física, todos os esforços da gestão da $\mathrm{BCH}$, junto ao Sistema de Bibliotecas da UFC, de estar proporcionando um ambiente favorável e confortável ao público, estão sendo percebidos pelos usuários da $\mathrm{BCH}$, talvez não no sentido consciente de que estão fazendo marketing de relacionamento para satisfazê-los, conquistá-los e fidelizá-los, mas no sentido de que algo foi feito para proporcionar seu bem-estar para que se sintam atraídos a estar na biblioteca. Ou seja, mesmo que a gestão da $\mathrm{BCH}$ não tenha estabelecido esforços com a intenção de fazer conscientemente marketing de relacionamento, seus esforços direcionados ao bem-estar dos usuários alcançaram o objetivo de satisfazê-los. Com o marketing de relacionamento, o que está satisfazendo pode ser potencializado para atingir um nível maior de satisfação, como se explica na última unidade de análise desta categoria.

\section{Satisfação com os serviços da BCH (Unidade de análise 3.3)}

Verificou-se o seguinte: dos vinte usuários que participaram da pesquisa, 14 disseram estar satisfeitos com os serviços prestados pela $\mathrm{BCH}$ e seis alegaram não 
estar satisfeitos com os serviços pelo fato de algumas pessoas que atuam no atendimento nem sempre estarem dispostas a prestar um bom atendimento e normalmente atendem com um expressivo mau humor. Segundo relatos da diretora da $\mathrm{BCH}$, por mais incentivo que haja por parte da direção para que todos os funcionários da biblioteca participem de cursos de capacitação, principalmente os que trabalham de forma direta com os usuários, para que aprimorem as relações pessoais com eles, assim como reuniões setoriais que têm por finalidade conscientizá-los a prestarem um atendimento com qualidade, ainda há funcionários que resistem se aprimorar para exercer suas funções com excelência.

Ainda segundo a diretora da $\mathrm{BCH}$, há funcionários que optaram pelo serviço público federal mesmo em um cargo inferior a sua formação e acabam se frustrando e demonstrando sua insatisfação aos usuários o que acaba implicando numa visão negativa da biblioteca como um todo.

Percebeu-se que a diretora da $\mathrm{BCH}$ tem consciência de que há uma grande lacuna que desfavorece a prestação de um serviço de atendimento com qualidade e, por consequência, acarreta um maior nível de insatisfação por parte dos usuários.

Em concordância com Godri (1994, p. 59), o marketing de relacionamento se apresenta como uma alternativa que viabiliza meios de lidar com esses entraves da forma favorável, pois ele busca integrar todos na sua filosofia potencializando as redes de relações com os usuários, primando pela ética, a qualidade e a boa convivência, adotando uma atitude de simpatia e empatia na oferta da informação.

\section{Grau de satisfação dos usuários da $\mathrm{BCH}$ (Unidade de análise 3.4)}

Percebemos que os julgamentos de valores quanto à satisfação, feitos pelos usuários participantes da pesquisa, não foram com base numa percepção das ações de marketing de relacionamento, mas com base nas suas percepções das ações praticadas no dia a dia da $\mathrm{BCH}$ por meio dos produtos, serviços e ambientação, independente do tipo de ação.

Verificou-se que a maior parte dos usuários que responderam a esse questionamento está satisfeita com as ações praticadas pela $\mathrm{BCH}$, o que atinge as perspectivas da diretora e dos bibliotecários de referência, que desenvolvem ações, com foco nos usuários, pensando em satisfazê-los. 
Em síntese, a seguir apresentam-se as principais análises que respondem diretamente aos objetivos específicos desta pesquisa.

De um modo geral, o conhecimento que a diretora e os bibliotecários de referência da $\mathrm{BCH}$ têm sobre marketing de relacionamento é limitado, pois têm uma noção parcial dos meios, mas os fins do marketing de relacionamento ainda não são bem visualizados por eles. Embora haja um interesse destes pelo estudo do tema.

É unanime entre a diretora e os bibliotecários de referência da $\mathrm{BCH}$ a visão da importância do marketing de relacionamento no apoio de suas atividades, embora haja um direcionamento dessa importância limitado para a propaganda de produtos e serviços.

Os bibliotecários em questão buscam: conhecer os usuários para melhor entendê-los e atendê-los; prestar um bom serviço, tanto de referência quanto de atendimento; ofertar produtos de acordo com as necessidades dos usuários; proporcionar uma ambientação favorável e confortável aos usuários; interagir e divulgar os produtos e serviços por meios dos eventos realizados pala $\mathrm{BCH}$.

Percebe-se que as ações de marketing de relacionamento não são praticadas de forma consciente, pois não têm intenção de fazer marketing de relacionamento, uma vez que focam os usuários pensando prioritariamente em satisfazê-los, e não necessariamente nas relações para fidelizá-los. Fica evidente, que pelo desconhecimento sobre o marketing de relacionamento, suas ações e todas suas potencialidades não sejam plenamente assimiladas para uma prática consciente e efetiva.

Por não haver ainda uma plena assimilação sobre o marketing de relacionamento por parte da diretora e dos bibliotecários de referência da $\mathrm{BCH}$ para uma prática de ações conscientes e efetivas, fica também uma lacuna quanto à percepção dos usuários em relação às práticas de marketing de relacionamento na $\mathrm{BCH}$.

Contatou-se que a maior parte dos usuários que responderam a esta pesquisa está satisfeita com as ações praticadas pela $\mathrm{BCH}$, independente do tipo de ação. O que não implica numa alta satisfação a ponto de proporcionar uma fidelização. 


\section{CONCLUSÃO}

Estando uma biblioteca universitária na condição de um organismo vivo e em desenvolvimento, inserida no exponencial mercado da informação, possuindo como principal produto a informação, como principal serviço o serviço de informação, e como sua razão de ser o usuário, e tendo que se manter viva e atuante, atraindo, conquistando e mantendo seus usuários diante das diversas possibilidades e recursos informacionais que os atraem e os afastam para além dos seus limites, fazse necessário que ela use da criatividade para envolver e reter seus usuários por meio de relacionamentos favoráveis e de lucratividade mútua.

Assim, o marketing de relacionamento surge como uma alternativa para as bibliotecas universitárias, pois busca de forma estratégica conhecer profundamente os usuários quanto as suas necessidades e desejos, não só no que tange ao concreto, mas também ao abstrato, para assim prever e se antecipar ao que esse público necessita e deseja, e com isso, proporcionar aos usuários um alto nível de satisfação, pela oferta de produtos e serviços de informação personalizados que excedam suas expectativas, e assim criem laços de afinidade emocional com o que está sendo ofertado e da forma como está sendo ofertado, gerando assim a fidelização dos usuários através de relacionamentos que implicam em benefícios mútuos, preenchendo as lacunas que, por ventura, venham a existir nas ações da biblioteca, como é o caso do objeto de estudo desta pesquisa, a $\mathrm{BCH}$, que apresenta algumas lacunas em suas ações.

Portanto, embora o marketing de relacionamento seja um assunto relativamente novo, principalmente no âmbito biblioteconômico, faz-se necessário que os profissionais dessa área busquem conhecê-lo para integrá-lo à sua esfera de atuação, com ações positivas que gerem uma maior qualidade dos produtos e dos serviços, bem como uma maior satisfação, e por consequência, a fidelização dos usuários e uma maior lucratividade. 


\section{REFERÊNCIAS}

AMARAL, S. A. Marketing na Ciência da Informação. Brasília: Editora da Universidade de Brasília, 2007.

Análise do consumidor brasileiro do setor de informação: aspectos culturais, sociais, psicológicos e políticos. Perspectivas em Ciência da Informação, Belo Horizonte, v. 1, n. 2, p. 207-224, jul./dez. 1996.

BAPTISTA, S. G. Técnicas de marketing para gestores de unidades de informação. In: AMARAL, S. A. (Org.). Marketing na ciência da informação. Brasília: UNB, 2007. p. 81-95.

COBRA, M. Administração de marketing no Brasil. São Paulo: Cobra Ed., 2003.

COSTA, A. R. Marketing promocional: descobrindo os segredos do mercado. São Paulo: Atlas, 1996.

FRAGA, N. E. B. et al. O marketing profissional e suas interfaces: a valorização do bibliotecário em questão. Perspectiva em Ciência da Informação, Belo Horizonte, v. 13, n. 2, p. 148-167, maio/ago. 2008.

GODRI, D. Conquistar e manter clientes. 32. ed. Blumenau-SC: Eko, 1994.

KOTLER, P. Administração de marketing. 10. ed. São Paulo: Atlas, 2000.

KOTLER, P.; KELLER, K. L. Administração de marketing. 12. ed. São Paulo, SP: Prentice Hall, 2006.

KOTLER, P.; ARMOSTRONG, G. Princípios de marketing. 9. ed. São Paulo: Pearson, 2004.

MCKENNA, R. Marketing de relacionamento. Rio de Janeiro: Campus, 1999.

MENDES, R. V. Marketing de relacionamento. 2007. 54 f. Monografia

(Especialização em marketing) - Universidade Candido Mendes, Rio de Janeiro, 2007. Disponível em: <http://www.avm.edu.br/monopdf

/24/RENATO\%20VILLELA\%20MENDES.pdf>. Acesso em: 13 ago. 2011.

MORAES, R. Análise de conteúdo. Revista Educação, Porto Alegre, v. 22, n. 37, p. 7-32, 1999.

OLIVEIRA, M. M. Como fazer pesquisa qualitativa. 2. ed. Petrópolis, RJ: Vozes, 2008.

OTTONI, H. M. Bases do marketing para unidades de informação. Ciência da informação, Brasília, v. 25, n. 2, p. 1-11, 1995.

ROCHA, Â. da; CHRISTENSEN, C. Marketing: teoria e prática no Brasil. 2. ed. São Paulo: Atlas, 1999. 
SANTOS, D. Fidelização de clientes. 2008. Disponível em: $<$ http://www.administradores.com.br/informe-se/artigos/fidelizacao-declientes/20882/>. Acesso em: 06 fev. 2015.

SILVA, A. F. G. Marketing em unidade de informação: revisão crítica. Revista de Biblioteconomia de Brasília, Brasília, v. 23/24, n. esp., p. 5-24, 1999/2000.

SILVEIRA, L. S. A ação cultural como estratégia de ampliação e fidelização dos usuários de bibliotecas públicas de Porto Alegre, RS. 2009. 82 f. Monografia (Graduação em Biblioteconomia) - Universidade Federal do Rio Grande do Sul, Porto Alegre, 2009. Disponível em: <http://www.lume. ufrgs.br/bitstream/handle/10183/22717/000740553. pdf?sequence=1>. Acesso em: 13 ago. 2011.

TEIXEIRA, L. R.; FREITAS, Z. B. Atendimento ao cliente. Cadernos Temáticos de Ciências Gerenciais, Sete Lagoas, n. 4, jul. 2004.

\title{
Title
}

Relationship marketing in academic libraries

\begin{abstract}
Introduction: It discusses the relationship marketing in university library, with the object of study the Care Sector to Reader of the Humanities Library $(\mathrm{BCH})$ of the Federal University of Ceará, and the relationship between reference librarians and users.

Objective: Investigate, with the direction and the reference librarians of $\mathrm{BCH}$, the knowledge they have about relationship marketing, to see the importance of making use of this type of marketing to better satisfy users that relationship marketing activities are practiced as are practiced and are practiced consciously, and verify, with library users, their perception of the practice and their degree of satisfaction when the developed relationship marketing.

Methodology: this study consists of an exploratory study with a qualitative approach. We used the functionalism and as a tool for data collection, we opted for the semi-structured interview and questionnaires. To analyze the data, we opted for the content analysis.

Results: It was found that the knowledge that the director of $\mathrm{BCH}$ and the reference librarians have on relationship marketing is still very restricted, and although they see the importance of the issue under the $\mathrm{BCH}$, the shares are practicing unconsciously, which leaves gaps in the perception of users in relation to these practices. Conclusions: regardless of the type of actions, users showed a considerable degree of satisfaction with the actions taken by the $\mathrm{BCH}$.
\end{abstract}

Key words: Marketing. Relationship marketing. University library. 


\section{Título}

La deconstrucción de estereotipos indeseables sobre el bibliotecario: el uso del marketing relacional en las bibliotecas universitárias

\section{Resumen}

Introducción: discute el marketing relacional en la biblioteca de la universidad, con el objeto de estudio del sector de atención al lector de la Biblioteca de Humanidades $(B C H)$ de la Universidad Federal de Ceará, y la relación entre los bibliotecarios de referencia y los usuarios.

Objetivo: Para investigar, con la dirección y los bibliotecarios de referencia del $\mathrm{BCH}$, el conocimiento que tienen sobre el marketing relacional, para ver la importancia de hacer uso de este tipo de marketing para satisfacer mejor a los usuarios que el marketing relacional actividades se practican como se practican y se practican conscientemente, y verificar, con los usuarios de la biblioteca, su percepción de la práctica y su grado de satisfacción cuando el marketing relacional desarrollado.

Metodología: consiste en un estudio exploratorio con abordaje cualitativo. Se utilizó el funcionalismo y como herramienta de recolección de datos, se optó por la entrevista y cuestionarios semi-estructurados. Para analizar los datos, se optó por el análisis de contenido.

Resultados: se encontró que el conocimiento de que el director del $\mathrm{BCH}$ y los bibliotecarios de referencia tienen en el marketing de relaciones es aún muy limitado, y aunque ven la importancia de la cuestión en el $\mathrm{BCH}$, las acciones están practicando inconscientemente, lo que deja lagunas en la percepción de los usuarios en relación con estas prácticas.

Conclusiones: independientemente del tipo de acciones, los usuarios mostraron un alto grado de satisfacción con las medidas adoptadas por el $\mathrm{BCH}$.

Palabras clave: Marketing. Marketing relacional. Biblioteca de la Universidad.

Recebido em: 14.09.2012

Aceito em: 28.04.2014 